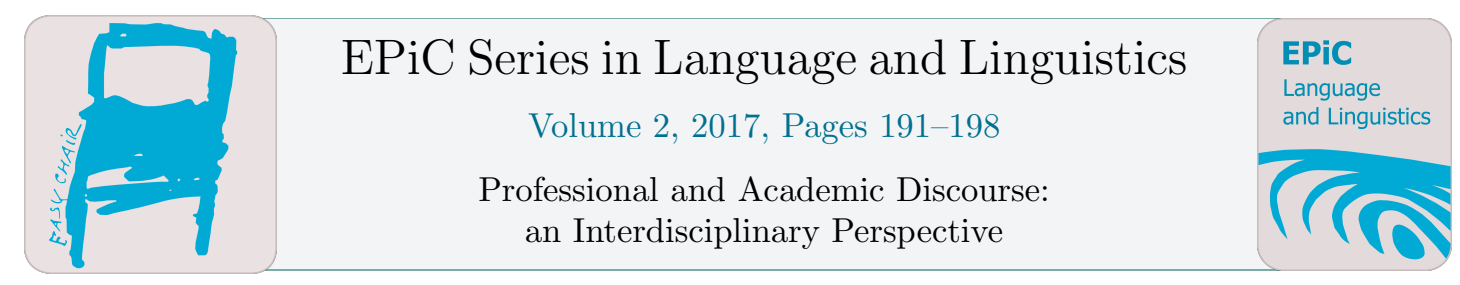

\title{
Cognitive Operations in Tropes: The Case of Parameterisation ${ }^{1}$
}

\author{
Javier Herrero Ruiz \\ Universidad Politécnica de Madrid \\ javier.herrero@unirioja.es
}

\begin{abstract}
Over the last few years, the study of cognitive operations from both a pragmatic and a cognitive angle (cf. Ruiz de Mendoza \& Galera, 2014) has gradually received more and more attention. According to Ruiz de Mendoza \& Galera (2014), parameterisation is based on world knowledge and is cued by the linguistic expression, resulting in the fixation of a generic value which is otherwise undefined to a greater or lesser extent, as in John drinks standing for 'John usually drinks alcohol' or Something has happened meaning 'something bad has happened.'

Following Herrero (2009), in this paper we attempt to analyse how parameterisation applies in some tropes (overstatement, understatement, euphemism, and dysphemism) by placing constraints on how far the operations that underlie them, strengthening and mitigation, can go.

The examples have been extracted from a multi-faced corpus compiled from The British National Corpus, The Corpus of American English, and Google searches.

Keywords: cognitive operations, tropes, parameterisation, Cognitive Linguistics, Pragmatics
\end{abstract}

\section{Introduction}

Over recent years, the study of cognitive operations from both a pragmatic angle (e.g. Bach, 1994; Recanati, 2004; Sperber and Wilson, 1995) and a cognitive angle (e.g. Ruiz de Mendoza and Peña, 2005; Ruiz de Mendoza and Santibáñez, 2003; Ruiz de Mendoza, 2005, 2011; Ruiz de Mendoza \& Galera, 2014) has gradually received more and more attention.

According to Ruiz de Mendoza \& Galera (2014), parameterisation operations involve the specification of general conceptual material on the basis of textual and contextual information. The opposite operation is generalization, which provides access to a general configuration from a more specific one. Parameterisation is based on world knowledge and is cued by the linguistic expression, resulting in the fixation of a generic value which is otherwise undefined to a greater or lesser extent, as 
in John drinks standing for 'John usually drinks alcohol' or Something has happened meaning 'something bad has happened.'

This operation has been thoroughly analysed in Ruiz de Mendoza \& Santibáñez (2003) and in Ruiz de Mendoza (2005); they claim that it is a very pervasive notion in language which is characterised by the fact that it poses weak demands on lexical and grammatical systems (which only need to code very generic values), thus placing a great burden of responsibility on inferential processes. In the literature, parameterisation has also been applied to explain instances of subsentential utterances (see Ruiz de Mendoza, 2005), which are not simply related to the elision of some conceptual material from what is said (as is the case of elliptical clauses) but, rather, include some attention-attracting features. This is the case of nice hunt, which is not simply elaborated on to mean 'That was a nice hunt indeed' but it contains a generic attitudinal element that has to be parameterised depending on the contextual features (e.g. 'That was a nice hunt indeed, and I was really impressed about it').

Following Herrero (2009), in this paper we attempt to analyse how parameterisation operations apply in some tropes (overstatement, understatement, euphemism, and dysphemism) by placing constraints on how far the operations that underlie them can go. In order to do so, we have created an ad hoc corpus extracted from The British National Corpus and The Corpus of American English; we have also made use of Google searches in order to further back up our initial hypotheses.

\section{Analysis}

\subsection{Overstatement}

According to Herrero (2009: 215), overstatement can be defined as the process whereby we can represent (prototypically scalar) concepts that are at a lower level by means of referring to the higherlevel magnitudes, with the objective of maximizing certain contextual effects. Overstatement generates a contrast based on the scalar difference existing between two different magnitudes: one that results from the linguistic expression and another which stems from the cognitive environment in which the overstated utterance is produced.

A well-known example of overstatement is the expression This suitcase weighs a ton (cf. Ruiz de Mendoza, 2002; Ruiz de Mendoza \& Santibáñez, 2003), which is based upon a scalar continuum of weight that can be represented as follows:

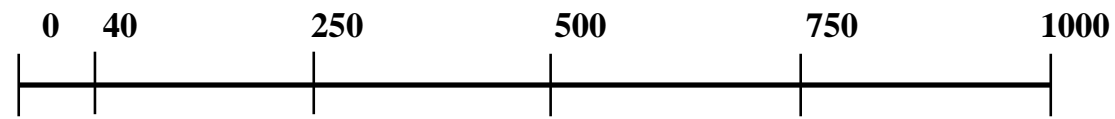

Figure 1. Scalar continuum for weight (from Herrero, 2009: 215)

Imagine that we utter this sentence when referring to a suitcase we want to move and whose real weight is 40 kilos or so (i.e. too much weight for just one person to lift). In doing so, both the speaker and the listener understand that the weight of the suitcase is lower than what has been expressed. In other words, the imaginary or figurative weight of the suitcase is represented as being more than it really is. In order to accomplish this complex mental process, the speaker and the hearer make use of two different cognitive operations, strengthening and mitigation respectively.

However, strengthening and mitigation are not the only operations that characterise overstatement. On certain occasions, parameterisation plays an essential role in fixing the scalar values to a greater or lesser extent that would be otherwise undefined. More specifically, parameterisation allows the speaker to focus on those aspects of the utterance that will guide the hearer's interpretation by placing constraints on how far the mitigation operation can go. In fact, there is a barrier to mitigation which is found in the point of the scale that is previous to the one overtly stated in the exaggerated expression. 
Let us exemplify this by means of Carston's example This steak is raw (2000). If we stick to our initial definition of overstatement (i.e. the representation of concepts that are actually at a lower level by means of referring to the higher-level magnitudes), we will easily observe that it does not work for, say, a scalar continuum in which the different degrees of cookedness are represented (see figure 2 below), as we are representing the concept of 'undercooked' by means of the concept 'raw.'

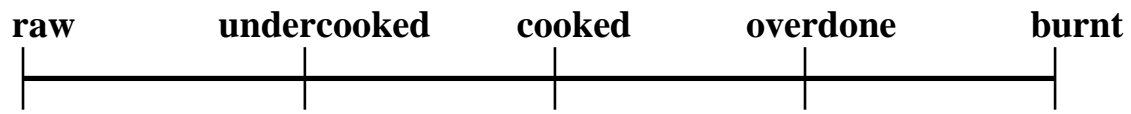

Figure 2. Scalar continuum for degrees of cookedness (Herrero, 2009: 216)

In order to solve this, the speaker and the hearer first follow a process of parameterisation of some of the values of the scale. They thus bring into focus the degrees corresponding to 'undercookedness,' leaving aside all the values related to 'overcookedness.' Thus, in This steak is raw we are dealing with a clear case of overstatement whereby the speaker has scaled 'undercooked' up to 'raw' through a strengthening operation, whereas the hearer's task is to scale 'raw' down to 'undercooked' via a mitigation operation. Similarly, if we utter the sentence This steak is burnt in order to say that it is very much overdone, we are fixing only those values that refer to degrees of 'overcookedness.' We could diagramme the whole scale as consisting of two separate subscales:

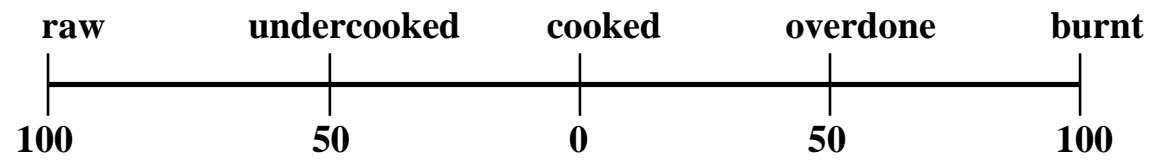

Figure 3. Scalar continuum for degrees of cookedness (Herrero, 2009: 216)

Consider now the expressions It is a hellish day and Heavenly day today; in the former, the speaker selects the values related to badness and rejects those concerning goodness, whereas in the latter the process is the opposite. This is how the parameterisation operation applies. Hence, in the case of the first expression the speaker reinforces 'bad' and reaches the term 'hellish', whereas in the second instance, we move from 'good' to 'heavenly'.

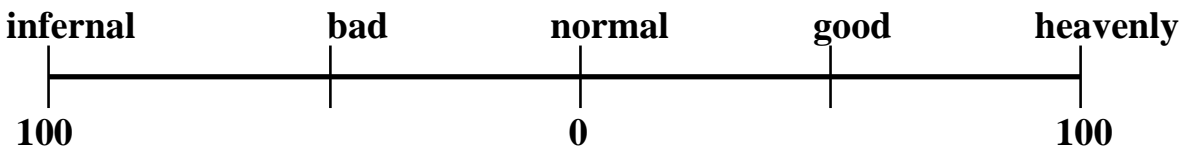

Figure 4. Scalar continuum for types of days (Herrero, 2009: 217)

\subsection{Understatement}

Although there are many labels for the different kinds of overstatement studied in the literature (e.g. hyperbole, extreme case formulation, auxesis, among others; cf. Pomerantz, 1986; McCarthy and Carter, 2004; Norrick, 2004), they are all produced and interpreted similarly. Despite the fact that we use the general term understatement to refer to the phenomenon which is opposite to overstatement in terms of the contextual effects produced (i.e. the model whereby we are able to lessen certain contextual effects), we shall distinguish between three different kinds of understatement as regards its mental creation and interpretation: meiosis, paradiastole, and litotes.

Meiosis can be described as the process whereby we can speak about actual higher-level dimensions by means of mentioning lower-level magnitudes (e.g. It's just a scratch referring to a 'sizeable wound'). As for paradiastole, we will consider it a case of euphemism (or dysphemism, see section 2.3) since it involves the axiology of the word (e.g. 'unattractive' for 'ugly,' 'uncivilised' for 'savage'). Finally, 
litotes can be defined as the denial of the opposite or contrary of which otherwise would be used (as the expression He is not a good cook to mean 'he is a bad cook'). As we shall see, whereas we can establish a twofold distinction between the speaker and hearer's perspectives for meiosis and paradiastole (which in fact are exactly the opposite of the model we have followed for overstatement), there is a common, unified model in litotes.

\subsubsection{Meiosis}

For the sake of illustration, we shall continue using the example of the suitcase but, now, in a context in which the speaker does not want any help and he can lift the suitcase on his own. So, he says: Bah, it's only 2 kilos! The expression is likewise based upon a scalar continuum of weight that can be represented as follows:

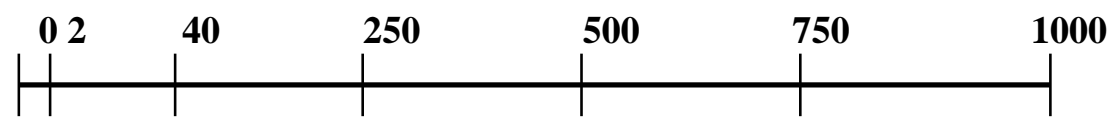

Figure 5. Scalar continuum for weight (Herrero, 2009: 230)

Obviously, in this expression the speaker has intentionally scaled down the weight of the suitcase. In other words, the imaginary or figurative weight of the suitcase is represented as being lower than it is. In order to accomplish this complex mental process, the speaker and the hearer undergo two different cognitive operations, mitigation and strengthening respectively.

However, as was the case with overstatement, strengthening and mitigation are not the only operations that characterise this figure. Sometimes, parameterisation also applies in order to determine the scalar values to a greater or lesser extent that would be otherwise undefined. This process allows the speaker to focus on those aspects of the utterance that will guide the hearer's interpretation by placing constraints on how far the mitigation operation can go. Now, there is a barrier to strengthening which is on the point of the scale that is previous to the one overtly stated in the mitigated expression. Let us consider the following example: imagine that someone is invited to a birthday party and when asked about the taste of an excessively sweet piece of cake, she remarks: Oh, it's a bit sweet.

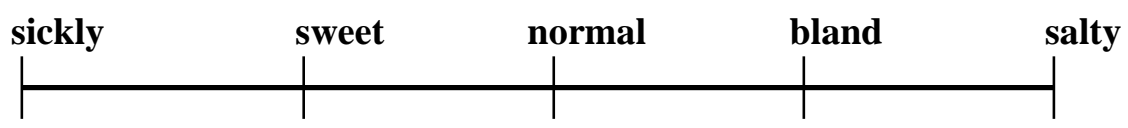

Figure 6. Scalar continuum for degrees of taste (Herrero, 2009: 231)

As was the case with overstatement, if we adhere to our initial definition of meiosis consistently (i.e. the process whereby we can speak about actual higher-level dimensions by means of mentioning lower-level magnitudes), we observe that it does not work for a scalar continuum in which the different degrees of taste are represented (see figure 6 above), as we are representing the concept 'sickly' by means of the concept 'sweet.' To solve this problem, the speaker and the hearer first follow a process of parameterisation of some of the values of the scale. Thus, they only pay attention to the values corresponding to 'sweetness,' leaving aside all the values related to 'saltiness'.

Because of this, in the expression It's a bit sweet, what we have in hand is an instance of meiosis whereby the speaker has scaled 'sickly' down to 'sweet' through a mitigation operation; the hearer's task is to scale 'sweet' up to 'sickly' via a strengthening operation. 


\subsubsection{Litotes}

According to Herrero (2009: 248-249), this figure should be analysed in the context of the pragmatic asymmetries produced by negation. These asymmetries have long been studied by pragmatists in terms of maxims analysis (e.g. Leech, 1983). First, we shall establish a contrast between the cognitive strategy in She's not pretty (by default meaning 'she is rather ugly') and the one in:

(1)

A: Do you drink? (i.e. 'drink alcohol').

B: I do not not drink (i.e. 'when it comes to drinking alcohol, the only thing I do is drink').

The expected answer is “Yes, I do" or “No, I don't," so B's response is certainly unusual and meant to have a special interpretation strategy. The reasoning strategy (i.e. the rationale) behind B's understanding of A's question and then behind her use of double negation is the following. Speaker A has asked me if I drink. Since all human beings drink liquids (e.g. water, milk, juices) to be alive, it is obvious that I drink, so speaker A must be asking about drinking something other than regular lifemaintenance or nourishing beverages. Alcoholic drinks are a prototypical case of non-nourishing beverage, so speaker A is most likely asking me if I drink alcoholic beverages. I would like to make it clear that there is nothing that, given the appropriate context, would deter me from drinking alcohol. Saying that I drink a lot or that I drink all the time does not convey this idea. However, negating the hypothetical assumption that I do not drink alcohol would indicate that the assumption is erroneous and therefore that I do drink alcohol when it comes to drinking alcohol. But then I could achieve the same communicative purpose by stating affirmatively I do, I drink alcohol. So negating the hypothetical assumption must convey to the addressee the idea that I am communicating more than what it literally conveys. This is accomplished via exaggeration: what double negation negates is not only the erroneous hypothetical assumption that I do not drink, but the scaled down assumption that if I drink alcohol, I drink small amounts of it (i.e. I drink little). Double negation then may result in the interpretation 'I do not drink just a little alcohol, I drink large amounts of it.'

In the case of She's not pretty, Geoffrey Leech (1983) has studied akin examples and accounted for them in terms of the Politeness Principle (especially the Tact Maxim), according to which we may use a weaker statement with the same implications as the stronger equivalent if this mitigates the impoliteness of a message.

She is ugly is stronger than She is not pretty, even though from a purely denotational point of view both can be said to refer to the same set of beings (those that are not beautiful). But it is stronger connotationally, i.e. from an axiological perspective. This way of using language creates an important asymmetry, since She's not ugly does not mean that she is beautiful. But here the PP does not need to come to the rescue of any potentially rude behaviour since neither She's beautiful nor She's not ugly are impolite utterances. So, negating the opposite of what would normally be said is not always litotes. Therefore, we shall refine the definition of this figure into "the negation of a certain word or expression in order to cover any point within the semantic space left out after the denial” (cf. Herrero, 2009: 249).

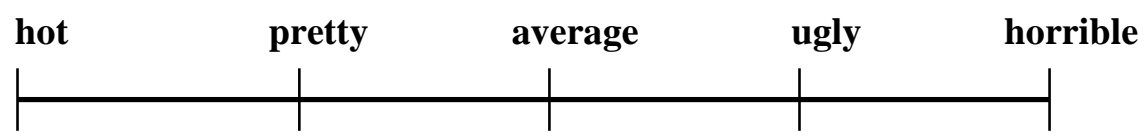

Figure 7. Scalar continuum for degrees of beauty/ugliness (Herrero, 2009: 250)

In She's not pretty the values corresponding to prettiness are overruled, and depending on the cognitive environment, the speaker and hearer refer to any value that may range from average to horrible. In fact, we have the option to fix the values, via parameterisation, to a greater extent; consider:

(2) She is not pretty.

(3) She is not pretty, she's horrible. 
(4) She is not pretty but not ugly.

(5) She is not pretty but definitely not ugly.

(6) No, she's not pretty. She's fucking beautiful.

(2), which can be considered the prototypical expression, apparently refers to any point in the scale with the exception of all the values corresponding to prettiness. In this case, it is the context which determines the specific point at which the value is eventually set. We can diagramme this example as follows:

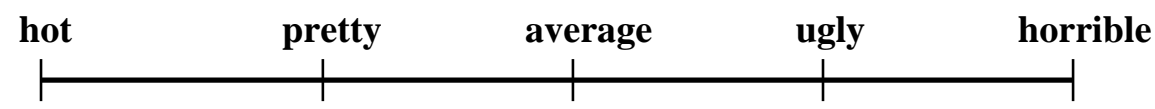

Figure 8. She is not pretty (Herrero, 2009: 250)

In (3) the value is fixed in the part of the scale that refers to ugliness. However, in (4) this value tends to be around the middle point of the scale. Also, in (5) the value is fixed at an average point but in this case it is nearer the scope of prettiness. Finally, (6) is intended to show that litotes is a cancellable trope, which can be represented this way:

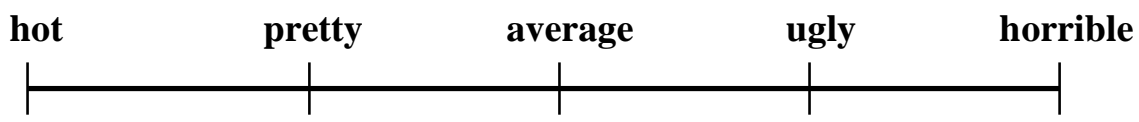

Figure 9. No, she's not pretty. She's fucking beautiful (Herrero, 2009: 250)

\subsection{Euphemism and Dysphemism}

As we are going to show, these tropes are derived the same way as overstatement and meiosis. However, the focus here lies on axiology since both euphemism and dysphemism can be interpreted on the basis of a scalar continuum based upon emotional and affective load. In this respect, we can represent concepts that are actually at a lower level by means of referring to the higher-level magnitudes in an axiological scale related to emotional and affective load (i.e. dysphemism). And the other way round, we can speak about actual higher-level dimensions by means of mentioning lower-level magnitudes (i.e. euphemism). Whereas euphemisms are characterised by a light emotional load, dysphemisms are related to a heavy affective load.

\subsubsection{Euphemism}

Speaker-based models of euphemism are based on mitigation operations whereby the speaker scales down the overall meaning impact of a given utterance in terms of its affective load. By means of those operations, the speaker produces some incongruity with her assumed hearer's cognitive environment. Let us illustrate this point with the following case. Imagine that a company is going to fire many of its employees because it is going to be privatised. When the managing director explains everything to the personnel, instead of using the word 'privatisation' she says structural adjustment. In so doing, she avoids the more direct term 'privatisation' by scaling down its emotional load.

In turn, hearer-based models of euphemism are subject to strengthening or reinforcement cognitive operations since the hearer moves from a lower to a higher value of the affective content of the concept represented. This is frequently done in order to retrieve the emotional nuances that the speaker wanted to minimise, after having noticed the contrast existing between the speaker's utterance and the hearer's cognitive environment. Hence, the addressee must strengthen the affective scalar content of the linguistic utterance and derive the value that is consistent with her cognitive environment. In the previous example, after contrasting the managing director's term with what the real case is, the hearer strengthens 'structural adjustment' into 'privatisation.' 


\subsubsection{Dysphemism}

Speaker-based models of dysphemism work on the basis of strengthening or reinforcement cognitive operations, since the addresser maximizes the emotional load of an utterance. This is usually done with the intention of creating certain contextual effects that the speaker wants to make salient to the ears of the listener. Together with the strengthening operation, the speaker generates some contrast with the cognitive environment which the listener is entitled to recognise in order to understand the expression as dysphemistic, and consequently obtain the full range of contextual effects. Let us exemplify this point with another term related to the business world, where we can dysphemistically refer to 'a tax increase concealed in price rises or other payments' as A stealth tax.

Hearer-based models of dysphemism are derived via the opposite operation, i.e. mitigation, as the listener moves from a higher to a lower value along the emotional scale of the concept that is represented. For the mitigation operation to ensue, the listener should be aware of the strengthening operation that the speaker has previously performed. This operation can be identified on the basis of contrast, since the speaker's reinforced concept stands in opposition to the information in her cognitive environment.

\subsubsection{Parameterisation in euphemism and dysphemism.}

Interestingly enough, the operations we have analysed above are not the only ones at stake. As Chamizo (2004) points out, the fact that a certain expression can be both used and understood as either euphemistic or dysphemistic is ultimately dependent on the context, usage of the utterance, or the speaker's intentions. More specifically, if we further analyse the cognitive operations that underlie the production and understanding of euphemisms and dysphemisms, there is a parameterisation operation on the part of both speaker and hearer that allows them to fix the values of the linguistic expression for its correct encoding and interpretation, and in accordance with the context of situation. In order to illustrate this point, let us have a look at how different expressions can be regarded as either euphemistic or dysphemistic depending on the context in which they are employed:

- FAMILIAR CONTEXT:

My uncle passed away > euphemism

My uncle died $>$ neutral

My uncle kicked the bucket $>$ dysphemism

- YOUNG CONTEXT:

My uncle passed away > dysphemism

My uncle kicked the bucket $>$ neutral

My uncle died > euphemism

\section{- COURT CONTEXT}

I'm going to the loo > euphemism

I'm going to the bathroom $>$ neutral

I'm going to the johnny $>$ dysphemism

- MILITARY CONTEXT:

I'm going to the loo > dysphemism

I'm going to the johnny $>$ neutral

I'm going to the bathroom > euphemism 


\title{
3 Conclusion
}

In this paper we have studied the two basic cognitive operations (mitigation and strengthening) that motivate the production and interpretation of the tropes under scrutiny: overstatement, understatement (including meiosis and litotes), and euphemism and dysphemism. Moreover, we have shown that parameterisation performs a key role in the generation of these linguistic processes by allowing the users of a language to fix the values of the linguistic expression for its correct encoding and interpretation, and in accordance with the context of situation, which ultimately conditions the utterance.

\author{
NOTES \\ ${ }^{1}$ Adapted from Herrero (2009).
}

\section{References}

Bach K. 1994. "Conversational implicature”, Mind and Language, 9: 124-262.

Carston R. 2000. "Explicature and semantics”, UCL Working Papers in Linguistics, 12: 1-44.

Chamizo P.J. 2004. "La función social y cognitiva del eufemismo y del disfemismo", Panacea, 5: 45-51.

Herrero J. 2009. Understanding Tropes: At the Crossroads between Pragmatics and Cognition. Frankfurt: Peter Lang.

Leech G. 1983. Principles of Pragmatics. London: Longman.

McCarthy M.J., Carter R.A. 2004. “There's millions of them: Hyperbole in everyday conversation”, Journal of Pragmatics, 36: 149-184.

Norrick N.R. 2004. "Hyperbole, extreme case formulation, Discussion note", Journal of Pragmatics, 36: 1727-1739.

Pomerantz A. 1986. "Extreme Case Formulations: A Way of Legitimizing Claims”, Human Studies, 9: 219-229.

Recanati F. 1989. “The pragmatics of what is said,” Mind \& Language, 4: 295-329.

Ruiz de Mendoza F. J. 2002. "From semantic underdetermination, via metaphor and metonymy to conceptual interaction”, Theoria et Historia Scientiarum, An International Journal for Interdisciplinary Studies, l.1: 107-143.

Ruiz de Mendoza F. J. 2005. "Linguistic interpretation and cognition”. In E. Croitoru, D. Tuchel \& M. Praisler (eds.), Cultural Matrix Reloaded. Romanian Society for English and American Studies. Seventh International Conference. Bucarest: Didactica Si Pedagogica. 36-64.

Ruiz de Mendoza F. J. 2011. "Metonymy and cognitive operations”. In R. Benczes, A. Barcelona, \& F. J. Ruiz de Mendoza (eds.), Defining metonymy in Cognitive Linguistics. Towards a consensus view. Amsterdam \& Philadelphia: John Benjamins. 103-123.

Ruiz de Mendoza F. J., Galera A. 2014. Cognitive modeling. A Linguistic Perspective. Amsterdam/Philadelphia: John Benjamins.

Ruiz de Mendoza F.J., Peña S. 2005. "Conceptual interaction, cognitive operations and projection spaces”. In F. J. Ruiz de Mendoza \& S. Peña (eds.), Cognitive Linguistics: Internal Dynamics and Interdisciplinary Interaction. Cognitive Linguistics Research. Berlin/New York: Mouton de Gruyter. 254-280.

Ruiz de Mendoza F.J., Santibáñez F. 2003. "Content and formal cognitive operations in construing meaning”, Italian Journal of Linguistics, 15(2): 293-320.

Sperber D., Wilson D. 1995. Postface to the second edition of Relevance: Communication and Cognition. Oxford: Blackwell. 